\title{
Inspirational Women in Surgery: Professor T. S. Kanaka, MS, PhD, Asia's First Woman Neurosurgeon
}

\author{
Krishnan Ganapathy ${ }^{1}$ - Savio George Barreto ${ }^{2,3}$
}

Accepted: 25 July 2021 / Published online: 10 August 2021

(C) Société Internationale de Chirurgie 2021

Professor Thanjavur Santhanakrishna Kanaka was born in Chennai (formerly known as Madras), India, on 31st of March, 1932 to Ms. Padmavathi (a home-maker) and Mr. Santhanakrishna (who worked as the Deputy Director of Public Instruction, and was also Principal of Madras Teacher's College)[1, 2]. She was one of eight siblings. While Professor Kanaka was drawn towards spiritual studies from an early age, it was her mother who persuaded her to join Medicine. Professor Kanaka's parents remained a strong source of inspiration and support to her throughout her professional journey [1].

Professor Kanaka graduated in Medicine (MBBS) from the prestigious Madras Medical College in December 1954. The streak of curiosity in this famous innovator was evident right from her early years in Medical school where she performed research projects culturing gonococcus with an aim to developing a vaccine for leprosy, an infamous disease that was highly prevalent in India at the time. She also studied the biochemical properties in cerebrospinal fluid specimens.

Sadly, Professor Kanaka's experiences during surgical training were marred by multiple encounters of gender discrimination reflective of the poor treatment of women in surgery at the time. She endured several instances where

Krishnan Ganapathy

drganapathy@apollohospitals.com

1 Apollo Telemedicine Networking Foundation, Apollo Hospitals, Tamil Nadu, 21, Greames Lane, Chennai 600086, India

2 College of Medicine and Public Health, Flinders University, Adelaide, South Australia, Australia

3 Division of Surgery and Perioperative Medicine, Flinders Medical Centre, Bedford Park, Adelaide, South Australia, Australia she would not be permitted to scrub into surgeries, and even had to re-attempt the qualifying exams multiple times to 'convince' the examiners of her determination to be a surgeon, and later, a neurosurgeon [2]. However, her resilience and tenacity were legendary and she remains a role model for all surgical trainees and surgeons both, male and female, alike. It was not all rough sailing though. She found supportive mentors in Professor A. Venugopal (Eminent Indian Urologist), Professors B Ramamurthi, V. Balasubramaniam and S. Kalyanaraman (Eminent Indian Neurosurgeons).

Professor Kanaka was a pioneer in the field of functional and stereotactic Neurosurgery [1]. She completed her doctorate $(\mathrm{PhD})$ in 1972 , evaluating the role of stereotactic surgery in the surgical management of cerebral palsy. She conducted research to determine the role of stereotactic procedures for involuntary movements, behavioural disorders, psychiatric disorders, epilepsy and spasticity, publishing sentinel papers in the field. She spent time at the University of California at Los Angeles in the 1980s doing a brief fellowship in stereotactic neurosurgery. She was actively involved in the nearly 1700 stereotactic operations (dentato-thalamotomy for infantile hemiplegia, neural stimulation for spasticity, stereotactic hypothalotomy, and functional neurosurgery for cerebral palsy [3-7]) (Fig. 1) performed over 15 years at the centre in Madras contributing to its International acclaim.

There was a lot more to this pioneer beyond neurosurgery. She enlisted in the Indian Army in 1962-1963 during the Indo-China war working as a medical officer in the Government General Hospital in Chennai. She holds the record (Limca Book of Records) for donating blood 139 times in her lifetime. Beyond the accolades and records was lady with a large and caring heart always looking for opportunities to help the underprivileged, 


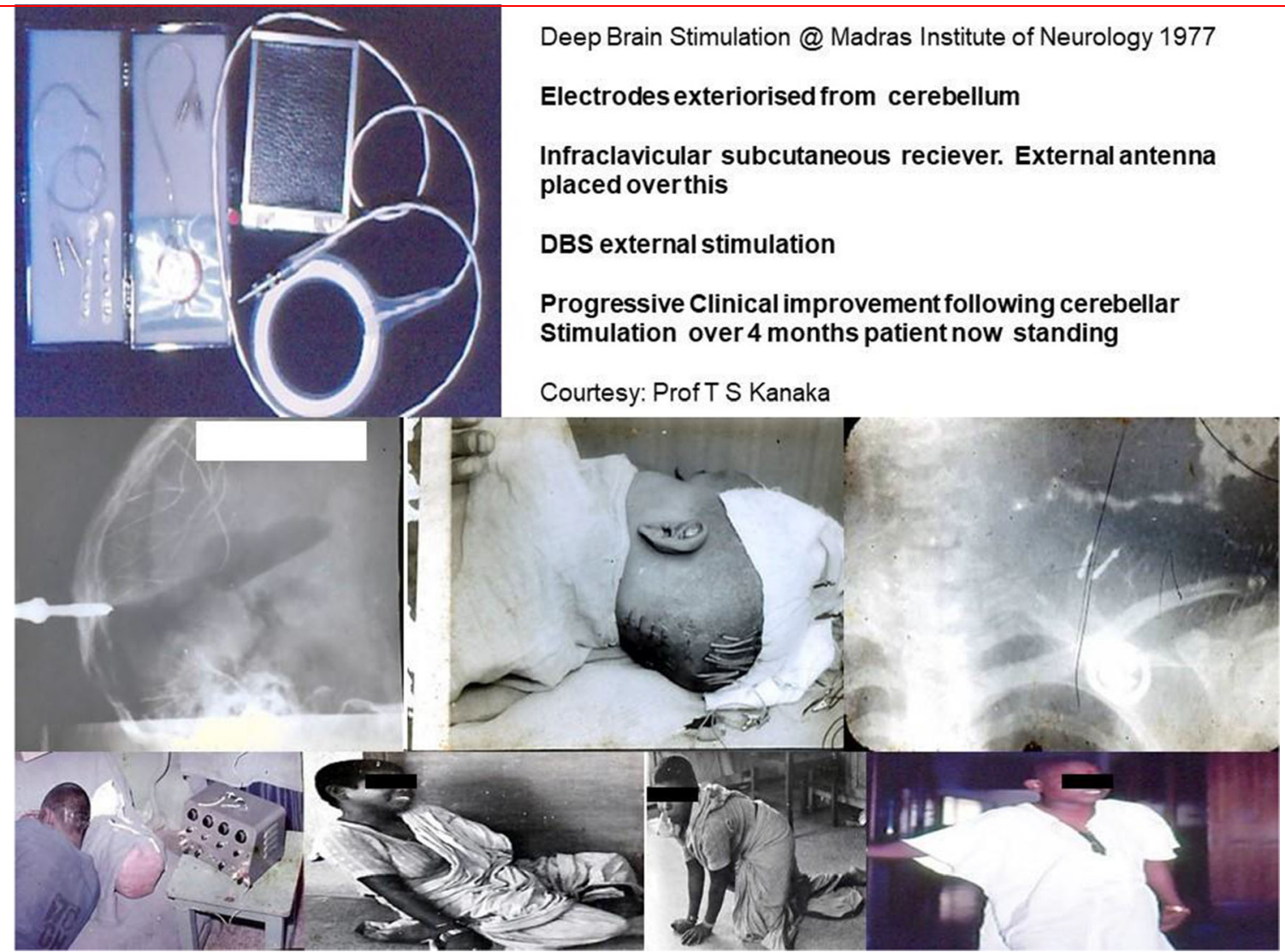

Fig. 1 A composite slide created by the Late. Professor T. S. Kanaka, and presented in 2011 at a Conference session entitled, the History of Stereotactic Surgery, highlighting her pioneering work before the advent of the computed tomography scan

driven by a deep sense of service. She worked with several organizations to provide healthcare to economically disadvantaged people. She established a Health Centre, named after her parents-the Sri Santhanakrishna Padmavathi Health Care and Research Foundation, using her savings. The foundation offers free healthcare to the needy in a country where nearly $70 \%$ of the population live in poverty.

Professor Kanaka passed away on the 14th of November, 2018. She was a strict disciplinarian who practiced what she preached. The lead author (Professor Ganapathy), who worked closely with Professor Kanaka (Fig. 2), fondly remembers her as an inspirational academician, surgeon and researcher who mentored numerous surgeons. She never let the constant discrimination she faced tarnish her perspective on life, nor the practice of medicine, having lived by the tenet "nothing is impossible".

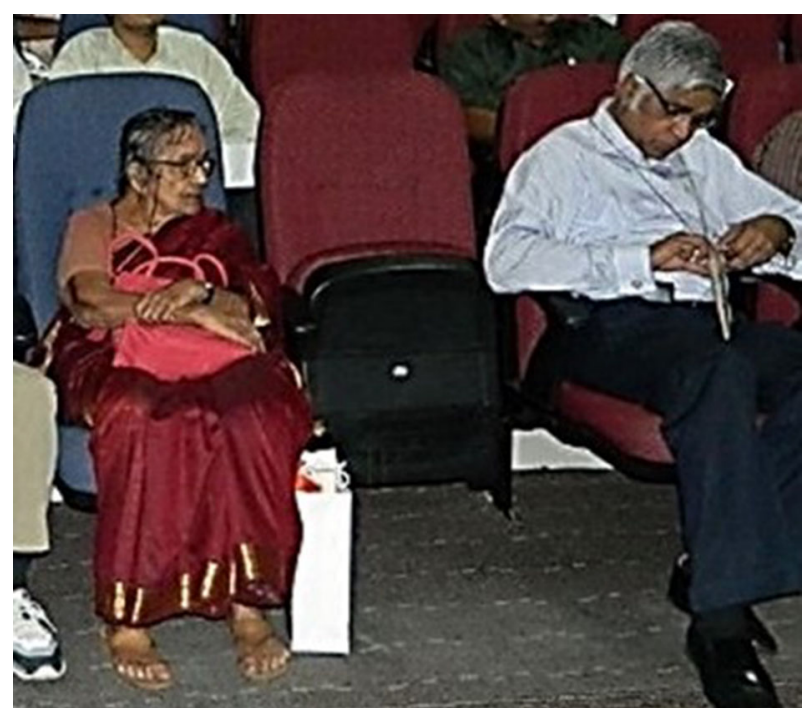

Fig. 2 Professor Thanjavur Santhanakrishna Kanaka and Professor K. Ganapathy attending the Indian Society of Stereotactic and Functional Neurosurgery Annual Conference in 2011 


\section{References}

1. Chidambaram S, Vasudevan MC, Pande A et al (2021) Dr. Thanjavur Santhanakrishna Kanaka-A Pioneer and Neurosurgical Innovator. World Neurosurg 150:84-88

2. Ganapathy K (2018) IN MEMORIAM: Thanjavur Santhanakrishna Kanaka (31(st) March 1932-14(th) Nov 2018). Neurol India 66:1872-1876

3. Balasubramaniam V, Kanaka TS (1981) Stereotaxic surgery in developing countries-a review. Zentralbl Neurochir 42:69-74

4. Balasubrammaniam V, Kanaka TS, Ramanujam PB (1974) Stereotaxic surgery for cerebral palsy. J Neurosurg 40:577-582
5. Balasubramaniam V, Kanaka TS, Ramanujam PB (1973) Stereotaxic cingulumotomy for drug addiction. Neurol India 21:63-66

6. Balasubramaniam V, Kanaka TS, Ramandujam PB et al (1973) Stereotaxic-hypothalamotomy. Confin Neurol 35:138-143

7. Kanaka TS, Balasubramaniam V, Ramanujam PB et al (1970) Stereotaxic surgery in cerebral palsy-a study of 57 cases. Neurol India 18(Suppl 1):56-59

Publisher's Note Springer Nature remains neutral with regard to jurisdictional claims in published maps and institutional affiliations. 